\section{THU0357 NAILFOLD CAPILLARY MICROSCOPY HAS LIMITED PROGNOSTIC VALUE IN PREDICTING FUTURE DEVELOPMENT OF CONNECTIVE TISSUE DISEASE IN CHILDREN WITH RAYNAUD'S PHENOMENON.}

G. Van der Kamp ${ }^{1}$, D. J. Mulder ${ }^{1}$, A. Van Roon ${ }^{1}$, A. Van Roon ${ }^{1}$, A. Van Gessel', W. Armbrust ${ }^{1}$ on behalf of Dept. of Internal Medicine, Division Vascular Medicine, University of Groningen, University Medical Center Groningen, Groningen, the Netherlands. ${ }^{1}$ UMCG, Groningen, Netherlands

Background: For adults with Raynaud's phenomenon (RP), nailfold capillary microscopy (NCM) is established to be an effective method for differentiating between PRP and SRP $(1,2)$. Although Raynaud's phenomenon (RP) is very common in childhood, studies on diagnostic methods to differentiate between primary RP (PRP) and secondary RP (SRP) at a young age are scarce $(3,4)$.

Objectives: The general aim of this study was to determine the prognostic value of nailfold capillary microscopy (NCM) in addition to antinuclear antibodies (ANAs) for later development of connective tissue diseases (CTD) in children with RP. Methods: This was a case-control study, in which 83 patients diagnosed with RP and having undergone NCM in childhood were retrospectively included. Based on whether they were diagnosed with a connective tissue disease (CTD) during follow-up, they were classified as PRP or SRP. PRP and SRP patients were compared on demographics, NCM and ANA positivity. Variables associated with SRP were included in a multivariate logistic regression model. Predictive values were calculated for NCM, ANA positivity and the combination of NCM and ANA positivity.

Results: At the time of the baseline NCM, the mean age of the RP patients was $15.4 \pm 2.3$ years. Averagely $6.4 \pm 3.2$ years after the baseline NCM, 65 of the 83 patients were classified as PRP and 18 as SRP. The most common CTDs were MCTD and undifferentiated CTD. ANA positivity was associated with SRP $(p<0.001)$. Of the NCM parameters, only capillary loss was associated with SRP $(p=0.01)$. Abnormal numbers of dilated capillaries, giant capillaries and haemorrhages were not significantly associated with SRP. In a multivariate logistic regression model, only ANA positivity was predictive for SRP (OR 11.19, Cl 3.0740.79). ANA alone had a sensitivity of $66.7 \%$ and a specificity of $85.9 \%$ for SRP. ANA combined with capillary loss had a sensitivity of $33.3 \%$ and a specificity of $96.8 \%$.

Conclusion: This study demonstrates that childhood RP is primary in most cases. Whereas RP in adulthood is most strongly associated with SSc, children with RP seem to be at risk of developing other CTDs with less apparent NCM abnormalities. Dilated capillaries, giant capillaries and haemorrhages on NCM are not associated with the spectrum of CTDs that children are at risk for, and do not differentiate between primary and secondary RP. Although capillary loss on NCM is associated with SRP, capillary loss may add little to the predictive value of serology. To clarify which NCM parameters are helpful for early detection of SSc-like CTDs, additional research is required.

References:

[1] Koenig M, Joyal F, Fritzler MJ, Roussin A, Abrahamowicz M, Boire G, et al. Autoantibodies and microvascular damage are independent predictive factors for the progression of Raynaud's phenomenon to systemic sclerosis: A twenty-year prospective study of 586 patients, with validation of proposed criteria for early systemic sclerosis. Arthritis Rheum. 2008;58(12): 3902-12.

[2] Pavlov-Dolijanovic S, Damjanov NS, Stojanovic RM, Vujasinovic Stupar NZ, Stanisavljevic DM. Scleroderma pattern of nailfold capillary changes as predictive value for the development of a connective tissue disease: a follow-up study of 3,029 patients with primary Raynaud's phenomenon. Rheumatol Int. 2012;32(10):3039-45.

[3] Jones GT, Herrick AL, Woodham SE, Baildam EM, Macfarlane GJ, Silman AJ. Occurrence of Raynaud's phenomenon in children ages 12-15 years: Prevalence and association with other common symptoms. Arthritis Rheum. 2003;48(12):3518-21.

[4] Pavlov-Dolijanović S, Damjanov N, Ostojić P, Sušić G, Stojanović R, Gacić $D$, et al. The prognostic value of nailfold capillary changes for the development of connective tissue disease in children and adolescents with primary Raynaud phenomenon: A follow-up study of 250 patients. Pediatr Dermatol. 2006;23(5):437-42.

Disclosure of Interests: None declared

DOI: 10.1136/annrheumdis-2020-eular.5014

\section{THU0358 NEGATIVE CHANGES OF BODY COMPOSITION IN MYOSITIS PATIENTS AND THEIR ASSOCIATION WITH DISEASE SPECIFIC CHARACTERISTICS, PHYSICAL ACTIVITY AND NUTRITIONAL STATUS.}

S. Oreska ${ }^{1,2}$, M. Špiritovic ${ }^{3}$, P. Česák ${ }^{3}$, O. Marecek ${ }^{3}$, H. Štorkánová ${ }^{1,2}$, B. Heřmánková ${ }^{3}$, K. Kubinova ${ }^{1,2}$, M. Klein ${ }^{1,2}$, L. Vernerová ${ }^{1,2}$, O. Růžičková ${ }^{1,2}$ K. Pavelka ${ }^{1,2}$, L. Šenolt ${ }^{1,2}$, H. Mann ${ }^{1,2}$, J. Vencovský ${ }^{1,2}$, M. Tomčík ${ }^{1,2} .{ }^{1}$ Institute of Rheumatology, Prague, Czech Republic; ${ }^{2}$ st Faculty of Medicine, Charles University, Department of Rheumatology, Prague, Czech Republic; ${ }^{3}$ Faculty of Physical Education and Sport, Charles University, Department of Physiotherapy, Prague, Czech Republic

Background: Skeletal muscle, pulmonary and articular involvement in idiopathic inflammatory myopathies (IIM) limit the mobility/self-sufficiency of patients, and can have a negative impact on body composition.

Objectives: The aim was to assess body composition and physical activity of IIM patients and healthy controls $(\mathrm{HC})$ and the association with selected inflammatory cytokines/chemokines and laboratory markers of nutrition and lipid metabolism.

Methods: 54 patients with IIM (45 females; mean age 57.7 ; disease duration 5.8 years; polymyositis (PM, 22) / dermatomyositis ( $\mathrm{DM}, 25)$ / necrotizing myopathy (IMNM, 7)) and 54 age-/sex-matched HC (45 females, mean age 57.7) without rheumatic/tumor diseases were included. PM/DM patients fulfilled Bohan/ Peter criteria for PM/DM. We assessed body composition (densitometry: iDXA Lunar, bioelectric impedance: BIA2000-M), physical activity (Human Activity Profile, HAP questionnaire), serum levels of 27 cytokines/chemokines (commercia multiplex ELISA kit, Bio-Rad Laboratories) and serum levels of selected parameters of nutrition and lipidogram. Disease activity (MITAX and MYOACT activity score) and muscle involvement (manual muscle testing, MMT-8, and functional index 2, FI2) were evaluated. Data are presented as mean \pm SD.

Results: Compared to $\mathrm{HC}$, patients with IIM had a trend towards significantly increased body fat \% (BF\%; iDXA: $39.9 \pm 7.1$ vs. $42.4 \pm 7.1 \%, p=0.077$ ), but significantly decreased lean body mass (LBM; iDXA: $45.6 \pm 8.1 \mathrm{vs.} 40.6 \pm 7.2 \mathrm{~kg}, p=0.001$ BIA: $52.6 \pm 8.8$ vs. $48.7 \pm 9.0 \mathrm{~kg}, p=0.023)$, increased extracellular mass/body cell mass $(E C M / B C M)$ ratio $(1.06 \pm 0.15$ vs. $1.44 \pm 0.42, p<0.001)$, reflecting deteriorated nutritional status and predisposition for physical activity, and significantly lower bone mineral density (BMD: $1.2 \pm 0.1$ vs. $1.1 \pm 0.1 \mathrm{~g} / \mathrm{cm}^{2}, p<0.001$ ). Disease duration negatively correlated with BMD and LBM-BIA. Disease activity (MITAX, MYOACT) positively correlated with LBM (by BIA and DXA), similarly as with basal metabolic rate (BMR), and fat free mass (FFM). CRP was positively associated with $\mathrm{BF} \%$ (BIA and DXA). Higher BF\%-DEXA was associated with worse physical endurance (FI2) and worse ability to perform physical activity (HAP) MMT-8 score negatively correlated with ECM/BCM ratio. Serum levels of several inflammatory cytokines/chemokines (specifically IL-1ra, MCP, IL-10) and markers of nutrition (specifically albumin, C3-, C4-complement, cholinesterase, amylase, insulin and C-peptide, vitamin-D, orosomucoid), and lipid metabolism (specifically triglycerides, high-density lipoprotein, apolipoprotein A and B, atherogenic index of plasma) were significantly associated with alterations of body composition in IIM patients. ( $p<0.05$ for all correlations)

Conclusion: Compared to healthy age-/sex-matched individuals we found significant negative changes in body composition of our IIM patients associated with their disease activity and duration, inflammatory status, skeletal muscle involvement, and physical activity. These data could reflect their impaired nutritional status and predispositions for physical exercise, aerobic fitness and performance.

Serum levels of certain inflammatory cytokines/chemokines and markers of nutrition and lipid metabolism were associated with alterations of body composition in IIM patients. This might further support the role of systemic inflammation and nutritional status on the negative changes in body composition of IIM patients.

Acknowledgments: Supported by AZV NV18-01-00161A, MHCR 023728, SVV 260373 and GAUK 312218

Disclosure of Interests: Sabina Oreska: None declared, Maja Špiritović: None declared, Petr Česák: None declared, Ondrej Marecek: None declared, Hana Štorkánová: None declared, Barbora Heřmánková: None declared, Kateřina Kubinova: None declared, Martin Klein: None declared, Lucia Vernerová: None declared, Olga Růžičková: None declared, Karel Pavelka Consultant of: Abbvie, MSD, BMS, Egis, Roche, UCB, Medac, Pfizer, Biogen, Speakers bureau: Abbvie, MSD, BMS, Egis, Roche, UCB, Medac, Pfizer, Biogen, Ladislav Šenolt: None declared, Heřman Mann: None declared, Jiří Vencovský: None declared, Michal Tomčík: None declared

DOI: 10.1136/annrheumdis-2020-eular.6050

THU0359

GENDER IMPACT ON LOWER URINARY TRACT INVOLVEMENT IN SYSTEMIC SCLEROSIS PATIENTS

G. Pacini ${ }^{1}$, S. Paolino ${ }^{1}$, F. Goegan ${ }^{1}$, P. F. Bica ${ }^{1}$, E. Alessandri ${ }^{1}$, C. Pizzorni ${ }^{1}$, A. Sulli', E. Gotelli ${ }^{1}$, F. Cattelan ${ }^{1}$, V. Smith ${ }^{2}$, M. Cutolo ${ }^{1} .{ }^{1}$ IRCCS San Martino Polyclinic Hospital, University Of Genoa, Research Laboratory and Academic Division of Clinical Rheumatology, Dept. Internal Medicine, University of Genova, Genoa, Italy; Research Laboratory and Academic Division of Clinical Rheumatology, Department of Internal Medicine, Genova, Italy; ${ }^{2}$ Ghent University Hospital; VIB Inflammation Research Center (IRC), Ghent University Hospital; Department of Internal Medicine; Department of Rheumatology; Unit for Molecular Immunology and Inflammation, Ghent, Belgium 
Background: Lower urinary tract symptoms (LUTS) are an underdiagnosed but frequent manifestation in systemic sclerosis (SSc) [1]. LUTS pathogenesis in SSc is undetermined, mainly involving dysautonomia, fibrosis and a possible antibody-mediated damage [2]. Divergently from general population, female sex and advanced age are not reported to significantly impact LUTS in SSc [2].

Objectives: To evaluate the potential influence of gender and hormone-related factors in LUTS prevalence and severity among SSc patients (Pts).

Methods: A population of 42 SSc Pts and 50 age- and sex-matched healthy subjects (HSs) was evaluated. SSc diagnosis was based on 2013 ACR/EULAR criteria. Demographic data, medications interfering with pelvic floor dynamics and general comorbidities commonly associated with LUTS - diabetes mellitus, chronic heart failure, chronic obstructive pulmonary disease, peripheral neuropathy, pelvic organ prolapse, fecal incontinence - were recorded. Validated self-reported questionnaires derived from the International Conference on Incontinence were used to assess prevalence and severity of LUTS, namely of urinary incontinence (UI) and overactive bladder (OAB) [3]. Data were analysed using non-parametric tests. A $p$ value $<0.05$ and a confidence interval $(\mathrm{Cl})$ of $95 \%$ were considered statistically significant.

Results: There were no significant differences in main demographic data between SSc Pts and HSs. Specifically, median age was 61 years (IQR 21-85) vs 57 years (IQR 28-93) and female prevalence $83 \%$ vs $84 \%$ in SSc Pts vs HSs, respectively. Amongst the female population, $83 \%$ of SSc Pts vs $84 \%$ of HSs was in post-menopausal state, with a median of 1 (IQR 0-3) vs 1 (IQR 0-4) pregnancy by natural route, respectively. No woman of the study had received hormone replacement therapy or local hormonal therapies prior to the study. Similarly, there were not any significant differences in analysed comorbidities, while ongoing treatment was significantly different between the two populations, SSc patients more frequently receiving calcium channel blockers and glucocorticoids than healthy subjects $(p<0.001)$. In SSc Pts, statistically significant correlation was observed between stress UI and sex, with an increased female-to-male ratio $(p<0.005)$, but any significant difference was observed in US distribution depending on parity and menopausal state, nor on other analysed variables. Interestingly, female dominance has not resulted as a significant predictive factor for LUTS prevalence or severity in SSc Pts. In fact, in the regression analysis, SSc disease was the only significant predictor for LUTS (OR $3.45,95 \% \mathrm{Cl} 1.41-7.95 ; \mathrm{p}<0.01$ ), independently of other analysed variables, particularly of gender and hormone-related factors.

Conclusion: This study confirms the absence of pathogenic female-gender participation in LUTS prevalence among SSc Pts. However, consistently with findings on general population, a significant increased prevalence of urinary symptoms, particularly of stress UI, in SSc female Pts has emerged [4]. It is therefore conceivable that hormonal factors may act as a catalytic circumstance rather than pathogenic players in LUTS progression during SSc disease.

References:

[1] John G et al. Arthritis Care Res (Hoboken) 2018;70(8):1218-27

[2] John G. Clin Rheumatol. 2020;39(1):5-8

[3] Abrams P et al, J Urol. 2006;175:1063-6

[4] Abelson B et al. Biol Sex Differ. 2018;9(1):45

Disclosure of Interests: Greta Pacini: None declared, Sabrina Paolino: None declared, Federica Goegan: None declared, Pietro Francesco Bica: None declared, Elisa Alessandri: None declared, Carmen Pizzorni: None declared, Alberto Sulli Grant/research support from: Laboratori Baldacci, Emanuele Gotelli: None declared, Francesco Cattelan: None declared, Vanessa Smith Grant/research support from: The affiliated company received grants from Research Foundation - Flanders (FWO), Belgian Fund for Scientific Research in Rheumatic diseases (FWRO), Boehringer Ingelheim Pharma $\mathrm{GmbH} \& \mathrm{Co}$ and Janssen-Cilag NV, Consultant of: Boehringer-Ingelheim Pharma GmbH \& Co, Speakers bureau: Actelion Pharmaceuticals Ltd, Boehringer-Ingelheim Pharma $\mathrm{GmbH} \&$ Co and UCB Biopharma Sprl, Maurizio Cutolo Grant/research support from: Bristol-Myers Squibb, Actelion, Celgene, Consultant of: Bristol-Myers Squibb, Speakers bureau: Sigma-Alpha

DOI: 10.1136/annrheumdis-2020-eular.4701

\begin{tabular}{|l|l}
\hline THU0360 & EFFICACY OF A SELF-TREATMENT PROTOCOL \\
FOR FACE AND TEMPOROMANDIBULAR JOINTS \\
REHABILITATION IN SYSTEMIC SCLEROSIS (SSC)
\end{tabular}

M. Passalacqua ${ }^{1}$, C. Foggi ${ }^{2}$, N. Mauro ${ }^{2}$, L. Tofani ${ }^{3}$, S. Guiducci ${ }^{3}$, C. Bruni ${ }^{3}$, G. Lepri ${ }^{3}$, J. Blagojevic ${ }^{3}$, K. El Aoufy ${ }^{3}$, G. Fiori ${ }^{3}$, F. Bartoli $^{3}$, S. Maddali Bongi ${ }^{4}$, M. Mitola ${ }^{5}$, M. Gizduloch ${ }^{6}$, M. Matucci-Cerinic ${ }^{3}$, S. Bellando Randone ${ }^{3}$. ${ }^{1}$ Fondazione IRCCS Don Carlo Gnocchi ONLUS, Florence, Italy; ${ }^{2}$ University of Florence, Florence, Italy; ${ }^{3}$ Department of Experimental and Clinical Rheumatology, University of Florence, Dept. Geriatric Medicine, Div. of Rheumatology, Florence, Italy; ${ }^{4}$ Associazione Multidisciplinare Riabilitazione
Reumatologica AMURR, Florence, Italy; ${ }^{5}$ ASSMAF ONLUS, Florence, Italy; ${ }^{6}$ Associazione Italiana Gnatologia, Florence, Italy

Background: In SSc, skin involvement of the face is frequent and extremely disabling, resulting in limited mouth opening, an altered dentition, difficulty in teeth care, as well as having a strong impact on the emotional and psychological well-being, thus impairing quality of life.

Objectives: to evaluate the efficacy of a self-treatment protocol (created by AMURR A Multidisciplinary Association of Rheumatological Rehabilitation) for face and tempomandibular joints (TMJs) rehabilitation with two devices used in the dental field.

Methods: 40 SSc patients (37 female and 3 male) with a mouth opening $\leq 40 \mathrm{~mm}$, were recruited and randomized in two groups of treatment: Group 1 (20 patients: mean age 50,650 yrs $\pm 13,937 \mathrm{SD}$, mean disease duraton 10,45 yrs $\pm 7,877 \mathrm{SD}$, opening mouth $32,250 \mathrm{~mm} \pm 5,590 \mathrm{SD}$ ) treated with a home self-treatment protocol consisting of 23 exercises carried out at home in front of a mirror, 22/23 exercises were performed once a day, one of these using a device to obtain uniform stretching of the buccal rhyme, another one usingused three times a day to reduce tension of muscles of the TMJs, facilitating the mouth opening; group 2 (20 patients: mean age 58,05 yrs $\pm 18,103$ SD, mean disease duration 17,4 yrs $\pm 15,017 \mathrm{SD}$, opening mouth $34,950 \mathrm{~mm} \pm 5,753$ ) without physical rehabilitation, only drugs as treatments of SSc and its complications. All patients underwent a baseline (T0) and 45 days (T1) clinimetric assessment by self-assessment of quality of life with SF-36 (Short-Form 36 Health Survey), of the degree of disability of the mouth with MHISS (of the Mouth Handicap in Systemic Sclerosis scale), Muscle pain evaluated by numerical rating scale (NRS) of the temporomandibular joint with TMD (Temporo mandibular Disorders), evaluation of mouth opening and ROM of the cervical spine. Statistical analysis was performed using the t-test or the Mann-Whitney test for assessing changes in all measurement scales between treatment groups.

Results: The protocol of home physiotherapy exercises resulted in a statistically significant improvement in the treated group compared to group 2 both for mouth opening (T0: $32,250 \pm 5,590, \mathrm{~T} 1: 35,650 \pm 6,046)$ vs (T0: $34,950 \pm 5,753 \mathrm{~T} 1$ : $34,300 \pm 6,001)(p<0.001)$, cervical flexion (T0: $2,950 \pm 1,939$ T1: $1.700 \pm 1,525)$ vs (T0: $4,450 \pm 2,282 \mathrm{~T} 1: 4,075 \pm 2,238)(\mathrm{p}<0.01)$, cervical extension (T0: 17,025 $\pm 1,895 \mathrm{~T} 1: 17,625 \pm 1,605)$ vs $(\mathrm{T} 0: 17,050 \pm 2,089 \mathrm{~T} 1: 16,525 \pm 3,110)(p<0.05)$ cervical right lateral flexion (T0: 14,075 $\pm 2,386$ T1:13,400 $\pm 2,431$ ) vs (T0: 14,200 $\pm 1,765 \mathrm{~T} 1: 14,425 \pm 1,742)(p<0.01)$, cervical right rotation (T0: 14,200 $\pm 3,416$ $\mathrm{T} 1: 13,750 \pm 3,206)$ vs (T0: 14,900 $\pm 1,683 \mathrm{~T} 1: 15,550 \pm 2,188)(\mathrm{p}<0.01)$, cervical left rotation (T0: 14,725 $\pm 3,640$ T1:14,450 \pm 3,710) vs (T0: $15,900 \pm 2,614$ T1 $16,450 \pm 2,964)(p<0.05)$, mouth disability at MHISS (T0: 19,100 $\pm 10,356$ T1: $16,000 \pm 9,989)$ vs (T0: $20,950 \pm 9,950, T 1: 21,100 \pm 10,775)(p<0.01)$.

Conclusion: The use of the home exercises protocol associated with the two devices has shown a significant improvement of the disability linked to skin involvement of the face. This highlights the fundamental role that home rehabilitation self therapy has in practice. These data will need to be confirmed in a larger cohort of patients

Disclosure of Interests: Mauro Passalacqua: None declared, Cristian Foggi: None declared, Nicola Mauro: None declared, Lorenzo Tofani: None declared Serena Guiducci: None declared, Cosimo Bruni Speakers bureau: Actelion, Eli Lilly, Gemma Lepri: None declared, Jelena Blagojevic: None declared, Khadija El Aoufy: None declared, Ginevra Fiori: None declared, Francesca Bartoli: None declared, Susanna Maddali Bongi: None declared, Marco Mitola: None declared, Marco Gizduloch: None declared, Marco Matucci-Cerinic Grant/research support from: Actelion, MSD, Bristol-Myers Squibb, Speakers bureau: Acetelion, Lilly, Boehringer Ingelheim, Silvia Bellando Randone: None declared

DOI: 10.1136/annrheumdis-2020-eular.3451

\section{THU0361 \\ EPIDEMIOLOGIC VARIATION ON SCLERODERMA RENAL CRISIS AND CLINICAL FEATURES VARIATION ON SYSTEMIC SCLEROSIS PATIENTS OVER TIME: DATA FROM RESCLE REGISTRY.}

X. Pla Salas ${ }^{1}$, C. Tolosa ${ }^{2}$, A. Guillén del Castillo ${ }^{3}$, M. E. Sánchez García ${ }^{4}$, J. Sánchez-Redondo ${ }^{5}$, E. L. Callejas-Moraga ${ }^{2}$, L. Sáez-Comet ${ }^{6}$, J. A. VargasHitos $^{7}$, J. A. Todolí Parra ${ }^{8}$, L. Trapiella Martínez ${ }^{9}$, I. Rodriguez-Pubto ${ }^{10}$, M. Freire ${ }^{11}$, I. Pons Martin del Campo ${ }^{1}$, V. Fonollosa-Pla ${ }^{3}$, C. P. Simeón-Aznar ${ }^{3}$, O. B. O. R. I. Autoimmune Diseases Study Group (Geas) ${ }^{12}$. 'Xarxa Assistencial Universitaria Althaia, Internal Medicine, Manresa, Spain; ${ }^{2}$ Corporación Sanitaria Universitaria Parc Taulí, Internal Medicine, Sabadell, Spain; ${ }^{3} \mathrm{Hospital}$ Universitario Vall d'Hebron, Unit of Autoimmune Diseases. Internal Medicine., Barcelona, Spain; ${ }^{4}$ Hospital Universitario Virgen de Valme, Internal Medicine, Sevilla, Spain; ${ }^{5}$ Hospital Universitario de Móstoles, Internal Medicine, Móstoles, Spain; ${ }^{6}$ Hospital Universitario Miguel Servet, Internal Medicine, Zaragoza, Spain; ${ }^{7}$ Hospital Universitario Virgen de las Nieves, Internal Medicine, Granada, 